\title{
Extreme pollution, climate change, and depression
}

\author{
Morteza Abdullatif Khafaie ${ }^{1}$ - Mehdi Sayyah ${ }^{2} \cdot$ Fakher Rahim $^{3}$ (I)
}

Received: 29 December 2018 / Accepted: 10 June 2019 / Published online: 21 June 2019

(C) Springer-Verlag GmbH Germany, part of Springer Nature 2019

One of the arguably most severe challenges facing the world in recent years is climate change. Rapid urbanization and the dramatic increase in $\mathrm{CO}_{2}$ emissions and short-lived climateforcing pollutants (SLCPs) mainly black carbon, ground level ozone, and sulfate has led to an increase in global warming, increased heavy precipitation wave, and increased sea level and tropical cyclone activity. However, existing city infrastructure has not been designed for this kind of threats. About one-third of the world population lives on the coast that may be at risk of flood. Heat in many regions especially the Middle East will be so extreme as so to make it routinely hazardous to be outside. The absence of effective infrastructure services, poorly designed and enforced regulations on air quality and waste management, contribute to the deterioration of air quality. A recent Lancet report has stated that air pollution contributed to the unacceptably high number of premature death (Cohen et al. 2017). Climate change does not just affect physical health by exacerbating health problems like respiratory and cardiovascular diseases, it can also pose mental health impacts such as depressive disorders and suicide (Gladka et al. 2018). For instance, studies indicate mental health disorders increased compared to reference data from 0.7 to $52.6 \%$ (Rataj et al. 2016). Undoubtedly, human behavior is depleting some of the natural resources ever faster, as well as degrading many parts of the environment, which leads largely to climate change and environmental decline (Tilman and Clark 2014). In addition, the human immune system is

\section{Responsible editor: Philippe Garrigues}

Fakher Rahim

Bioinfo2003@gmail.com

1 Social Determinants of Health Research Center, Ahvaz Jundishapur University of Medical Sciences, Ahvaz, Iran

2 Education Development Center (EDC), Ahvaz Jundishapur University of Medical Sciences, Ahvaz, Iran

3 Research Center of Thalassemia \& Hemoglobinopathy, Health Research Institute, Ahvaz Jundishapur University of Medical Sciences, Ahvaz, Iran heavily affected by increasing or decreasing of temperature (KhafaieMA and Mojadam 2016) (Dittmar et al. 2014). Therefore, it can be said that atmospheric conditions are also one of the environmental variables that can play an important role in our human physical and mental health (Wu et al. 2016), while this has not been much addressed by researchers.

Researchers at different levels of society have shown that increasing the duration and intensity of sunlight plays a very important role in increasing the satisfaction of individuals relative to their surroundings (Huisman et al. 2012, Keniger et al. 2013). Accordingly, researchers are trying to find out the main cause of the prevalence of depression among people regarding climate change (Majeed and Lee 2017; Padhy et al. 2015), so the results can be used to measure the impact of climate change on human's psychological and mental health on a wider scale. Besides, many people are aware of the dangers of rising temperatures, especially the effects of exposure to sunlight, on the increase of the risk of malignancies such as skin cancer (Armstrong and Cust 2017), but are less likely to be aware of the increase in the number of people suffering from mental health. Therefore, it can be said that the climate can play a very important role in the physical and mental health of individuals. People who are exposed to air pollution do not intend to have social communication; therefore, air pollution can also affect human relationships (Qian et al. 2016).

A depressed person always sees the world gray and dusty; thus, too many "bad air days,", the world becomes depressive, dusty, and darker. In addition, people's decision-making ability becomes weaker and they feel less energetic, bored, and tired during polluted days; thus, these factors make depression and symptoms more severe. In air pollution condition, anxious people also experience more concerns about the future.

The researcher reported that air pollution may increase the risk of some psychological disorders such as autism (Jung et al. 2013). Besides, patients with obsessive-compulsive disorder (OCD) are also likely to become more problematic when to be exposed to air pollution (Qian et al. 2016). Such people always have a lot of attention to their bodies and, in the case of 
air pollution, constantly think that they have become ill. This feeling leads to exacerbation of OCD in them and has a "hypochondriasis". Healthy people may be concerned more about their health status. In air pollution, the percentage of air elements has changed and oxygen levels are reduced. This leads to some degree of impatience, boredom, and aggressiveness and more tiredness than ever. Certainly, when oxygen is low, the feeling of fatigue will be doubled, and consequently, stress cannot be avoided (Sung et al. 2005).

Collectively, depression is a global crisis and is a curable disease as well; thus, it is known that effective scientific interventions can treat it. Unfortunately, most people with depression do not receive proper care and treatment. In some countries, out of every ten people with depression, there is only one person who receives appropriate treatment. So, the lack of adequate access to appropriate health services and social stigma around psychiatric illness are the main barriers to help such people. Among healthy individuals and those with chronic diseases, the use of health service increase in association with higher levels of exposure to air pollution. Future research on all health consequences of air pollution alongside health service economics would do well to measure the utility of targeted air quality advisories to reduce the risk, as well as increase the quality of life of people living in highly polluted areas. Recently, global warming, as well as climate change, brought hottest summers to many places globally, especially in gulf countries.

Given the first global survey, released by the World Health Organization (WHO), cities in Iran, India, and Pakistan rank among the worst on the planet for air pollution, (Gakidou et al. 2016) at the same time, most affected by anxiety, schizophrenia, and bipolar disorder. Asia has an especially low density of psychiatrists, despite, high overall burden of mental illness. Europe has the highest, led by Monaco, Norway, Belgium, and the Netherlands, each with between 20 and 40 psychiatrists per 100,000 people. The USA and Canada have about 13 psychiatrists per 100,000 people, according to the WHO report.

Reducing the future health risk of extreme climate warming interrelated with action to mitigate $\mathrm{CO}_{2}$ emission and SLCPs. Unlike $\mathrm{CO}_{2}$, by contrast, SLCPs have shorter atmospheric lifetimes; thus, mitigating SLCPs would be a quick action to improve both air quality and the climate. For this to be done, identifying the sources of SLCPs and control plans are key challenges. As recently, Australian health professionals made a statement on climate change and health; to limit global warming to $2{ }^{\circ} \mathrm{C}$, it is recommended the bulk of current oil, gas, and coal reserves should remain unused. Air pollution from fuel burning is responsible for many health problems and deaths around the world. Disruptions in climate are currently strengthening the frequency, severity, and duration of severe weather conditions such as heating, volcanic eruptions, droughts, and tropical storms that cause damage to livelihoods and human health. Countries should immediately commit to adopting alternative energy production strategies that put fewer greenhouse gases in the atmosphere.

Given that the mental health effects of extreme climate change and pollution such as depression can contribute to the destabilization of a community, offering a number of possible moves as governmental and health service intervention, and building social connections and fostering confidence in people's own resilience, as well, could help people and communities combat such unwanted health effects. One such program must be supported by proper data generation, compilation, and analysis to ensure that the action plans drawn up are optimal and will yield the desired results. All other siloed response measures are unlikely to be effective. As many people live in cities and countries which experiencing extreme climate changes subsequent of rising air pollution, nowadays, several countries facing many pieces of evidence that revealed the little attention from governments and people themselves to these destructive effects that clearly will transfer to our next generation. Therefore, it is important to send such messages to scientific communities, people, and health service providers to shift the resources alongside education interventions to combat these problems.

\section{Compliance with ethical standards}

Conflict of interest The authors declare that they have no conflict of interest.

\section{References}

Armstrong BK, Cust AE (2017) Sun exposure and skin cancer, and the puzzle of cutaneous melanoma: a perspective on Fears et al. Mathematical models of age and ultraviolet effects on the incidence of skin cancer among whites in the United States. American Journal of Epidemiology 1977; 105: 420-427. Cancer Epidemiol 48:147156

Cohen AJ, Brauer M, Burnett R, Anderson HR, Frostad J, Estep K, Balakrishnan K, Brunekreef B, Dandona L, Dandona R, Feigin V, Freedman G, Hubbell B, Jobling A, Kan H, Knibbs L, Liu Y, Martin R, Morawska L, Pope CA III, Shin H, Straif K, Shaddick G, Thomas M, van Dingenen R, van Donkelaar A, Vos T, Murray CJL, Forouzanfar MH (2017) Estimates and 25-year trends of the global burden of disease attributable to ambient air pollution: an analysis of data from the Global Burden of Diseases Study 2015. Lancet 389: 1907-1918

Dittmar J, Janssen H, Kuske A, Kurtz J, Scharsack JP (2014) Heat and immunity: an experimental heat wave alters immune functions in three-spined sticklebacks (Gasterosteus aculeatus). J Anim Ecol 83: 744-757

Gakidou E, Afshin A, Abajobir AA, Abate KH, Abbafati C, Abbas KM, Abd-Allah F, Abdulle AM, Abera SF, Aboyans V (2016) Global, regional, and national comparative risk assessment of 79 behavioural, environmental and occupational, and metabolic risks or clusters of risks, 1990-2016: a systematic analysis for the Global Burden of Disease Study 2016. Lancet 390:1345-1422 
Gladka A, Rymaszewska J, Zatonski T (2018) Impact of air pollution on depression and suicide. Int J Occup Med Environ Health 31:711721

Huisman ERCM, Morales E, van Hoof J, Kort HSM (2012) Healing environment: a review of the impact of physical environmental factors on users. Build Environ 58:70-80

Jung CR, Lin YT, Hwang BF (2013) Air pollution and newly diagnostic autism spectrum disorders: a population-based cohort study in Taiwan. PLoS One 8:e75510

Keniger LE, Gaston KJ, Irvine KN, Fuller RA (2013) What are the benefits of interacting with nature? Int J Environ Res Public Health 10: 913-935

KhafaieMA Y, Mojadam M (2016) Association between ambient temperature and blood biomarker of systemic inflammation in (C-reactive protien) in diabetes patients. Arch Med 8:3

Majeed H, Lee J (2017) The impact of climate change on youth depression and mental health. Lancet Planet Health 1:e94-e95

Padhy SK, Sarkar S, Panigrahi M, Paul S (2015) Mental health effects of climate change. Indian J Occup Environ Med 19:3-7

Qian Z, Liang S, Yang S, Trevathan E, Huang Z, Yang R, Wang J, Hu K, Zhang Y, Vaughn M, Shen L, Liu W, Li P, Ward P, Yang L, Zhang W, Chen W, Dong G, Zheng T, Xu S, Zhang B (2016) Ambient air pollution and preterm birth: a prospective birth cohort study in Wuhan, China. Int J Hyg Environ Health 219:195-203

Rataj E, Kunzweiler K, Garthus-Niegel S (2016) Extreme weather events in developing countries and related injuries and mental health disorders - a systematic review. BMC Public Health 16:1020

Sung EJ, Min BC, Kim SC, Kim CJ (2005) Effects of oxygen concentrations on driver fatigue during simulated driving. Appl Ergon 36:2531

Tilman D, Clark M (2014) Global diets link environmental sustainability and human health. Nature 515:518-522

Wu X, Lu Y, Zhou S, Chen L, Xu B (2016) Impact of climate change on human infectious diseases: empirical evidence and human adaptation. Environ Int 86:14-23

Publisher's note Springer Nature remains neutral with regard to jurisdictional claims in published maps and institutional affiliations. 